\title{
Penile metastasis from primary transitional cell carcinoma of the bladder sparing the urethra
}

\author{
Justin D. Oake, MD;1 Douglas N. Drover, MD, FRCSC ${ }^{2}$ \\ 'Section of Urology, University of Manitoba, Winnipeg, MB, Canada; '2Division of Urology, Memorial University of Newfoundland, St. John's, NL, Canada
}

Cite as: Can Urol Assoc J 2016;10(11-12):E392-4. http://dx.doi.org/10.5489/cuaj.3532

Published online November 10, 2016.

\section{Abstract}

Metastatic involvement of the penis is relatively infrequent. Metastasis of transitional cell carcinoma (TCC) is extremely rare. We report a case of bladder TCC with metastases to the penis that spares the urethra - a finding that, to the best of our knowledge, has not been previously reported. Of the documented mechanisms of metastatic transmission to the penis, we suspect the cause was retrograde lymphatic spread. In our case, a 59-year-old male presented to our clinic initially with phimosis and later developed gross hematuria. Subsequent cystoscopy noted the appearance of tumour extending into the prostate, as well as the appearance of extensive TCC throughout the bladder. Following transurethral resection of prostate and bladder tissue, which demonstrated high-grade urothelial carcinoma, the patient underwent a radical cystoprostatectomy. A year later, he developed worsening gross hematuria and we noted the appearance of primary penile squamous cell malignancy. He then underwent a partial penectomy. The histopathology evaluation result from the partial penectomy revealed infiltration of TCC in the glans penis, as well as invasion into the corpus spongiosum, with sparing of the urethra.

\section{Introduction}

Penile cancer is rare in North America and Europe. It accounts for less than $1 \%$ of cancers in men in the U.S. The incidence of disease is more common in South America, Southeast Asia, and parts of Africa. ${ }^{1}$ In the U.S., it is estimated that only 1820 new cases of penile cancer will be diagnosed in 2015. ${ }^{2}$ Metastatic involvement of the penis is a rare disease, ${ }^{3,4}$ with approximately 480 reported cases. $^{5}$ Nearly $75 \%$ of the metastases originate from adjacent urogenital organs. The most common sites include the bladder and prostate. ${ }^{6-8}$ The prognosis for these patients is very poor, as it typically indicates widespread metastatic disease. ${ }^{4,5,9}$ We present the first case of penile metastasis from primary transitional cell carcinoma (TCC) of the bladder that spares the urethra.

\section{Case report}

A 59-year-old male was initially referred in 2010 with a presentation of phimosis. He had been having increasing difficulties voiding. Patient underwent partial circumcision with a dorsal slit. Pathology revealed lichen sclerosis (balanitis xerotica obliterans) and was negative for dysplasia or malignancy.

The patient began to develop gross hematuria in 2013. Subsequent cystoscopy in 2013 revealed a normal distal urethra, while the prostate had an appearance of papillary tumour extending into the prostatic lumen. Proximally, it looked as if the whole prostate was replaced with TCC. There appeared to be extensive TCC throughout the bladder, obscuring the trigone. Prostate and bladder TCC was resected. Transurethral resection of the prostate tissue demonstrated high-grade urothelial carcinoma with focal stromal invasion. Transurethral resection of the bladder lesion revealed invasive high-grade papillary urothelial carcinoma with lamina propria and lymphovascular invasion, however, there was no invasion of the muscularis propria.

Cystoprostatectomy was considered, but given his morbid obesity (body mass index [BMI] of 62), and other comorbidities, he was referred for chemoradiation. After four and a half weeks of treatment with chemoradiation, cystoscopy showed no resolution of the tumour.

The decision was then made to undergo a radical cystoprostatectomy in 2014. Given his abdominal obesity, the transverse colon was used as a conduit. Postoperatively, the patient had some minor bleeding per urethra, which settled. Over time, the bleeding began to progress and he also began to experience pain. A followup computed tomography (CT) scan showed a new lymph node in the right groin with no other evidence of disease.

Following worsening bleeding from the urethra in 2015, examination suggested penile linear thickening, which was suspected to be recurrent TCC in the urethra. The decision was then made to undergo a full urethrectomy with right inguinal lymph node dissection. There was difficulty early in the operation while trying to pass a cystoscope through the urethra. Dorsal and ventral slits were made in the foreskin. 
Surprisingly, there was the appearance of primary penile squamous cell malignancy extending from the glans penis to the foreskin. A partial penectomy was subsequently performed. Pathology showed invasive TCC of the penis (pT2 $\mathrm{N} 2 \mathrm{Mx}$ ), invasive TCC of the foreskin, one of four right inguinal lymph nodes positive for metastases, however, the urethra was negative for carcinoma.

Pathological examination from the partial penectomy revealed, infiltration of carcinoma in the glans penis (Fig. 1), as well as invasion into the corpus spongiosum with sparing of the urethra (Fig. 2). According to immunohistochemical studies, staining with cytokeratin 7 revealed invasion of papillary and lesional cells in the penis, which is concordant with metastatic invasive TCC (Fig. 3).

\section{Discussion}

Although the incidence of metastatic penile cancer is quite rare, it is surprising considering the multiple metastatic mechanisms of spread. The five most accepted mechanisms of spread include: retrograde venous route; retrograde lymphatic route; arterial spread; direct extension; and implantation and secondary to instrumentation. ${ }^{4}$ As there are reports of TCC seeding after iatrogenic procedures, ${ }^{3,10}$ we cannot rule this out as a mechanism of spread. It is, however, unlikely in our case, considering that this was an isolated lesion without concurrent urethral involvement.

The prognosis for bladder carcinoma with penile metastasis is quite poor, only 3.9 months from diagnosis. The optimal treatment for penile metastasis requires a multidisciplinary approach, which offers the best chances for survival at approximately 9.2 months. ${ }^{6}$ The treatment options are usually local tumour excision, external beam radiation therapy, brachytherapy, chemotherapy, or partial or total penectomy.

\section{Conclusion}

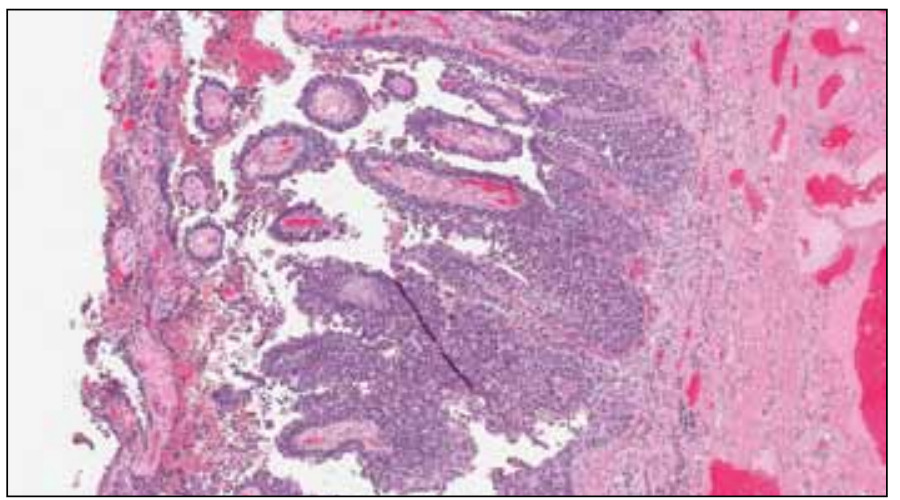

Fig. 1. Lesion with papillary/villous non-invasive growth pattern of glans penis (200x).
While the most accepted mechanism of penile metastatic spread from primary carcinoma in the bladder is via retrograde venous flow, ${ }^{6,11,12}$ we suspect that retrograde lymphatic spread would be more likely in this case. Penile skin, foreskin, and superficial fascia are rich in lymphatic supply. Consequently, the lack of urethral involvement may be explained due to the spread occurring via direct and indirect pelvic lymph nodes. ${ }^{5}$ This case highlights the importance of palpating the inguinal area for adenopathy in cases of urogenital neoplasms.

Competing interests: The authors report no competing personal or financial interests.

This paper has been peer-reviewed.

\section{References}

1. Pettaway CA, Davis JW. Contemporary management of penile carcinoma. Part 1: Overview of epidemioogy, diagnosis, staging, and management of the primary tumour. AUA Update Series 2012;31:15.

2. American Cancer Society. [updated 2015 July 7]. Available at http://www.cancer.org/cancer/penilecancer/detailedguide/penile-cancer-key-statistics. Accessed August 24, 2015.

3. Akman Y, Cam K, Kavak A, et al. Extensive cutaneous metastasis of transitional cell carcinoma of the bladder. Int J Urol 2003;10:103-4. http://dx.doi.org/10.1046/j.1442-2042.2003.00571.x

4. Cherian J, Rajan S, Thwaini A, et al. Secondary penile tumours revisited. Int Semin Surg Oncol 2006;3:33. http://dx.doi.org/10.1186/1477-7800-3-33

5. Zhang $\mathrm{K}, \mathrm{Da} \mathrm{J}, \mathrm{YaO} \mathrm{HJ}$, et al. Metastatic tumours of the penis: A report of 8 cases and review of the literature. Medicine 2015;94:132. http://dx.doi.org/10.1097/MD.0000000000000132

6. Berger AP, Rogatsch $\mathrm{H}$, Hoeltt $\mathrm{L}$, et al. Late penile metastasis from primary bladder carcinoma. Urology 2003;62:145.http://dx.doi.org/10.1016/S0090-4295(03)00239-5

7. Morichetti D, Mazzucchelli R, Lopez-Beltran A, et al. Secondary neoplasms of the urinary system and male genital organs. BJU Int 2009;104:770-6. http://dx.doi.org/10.1111/i.1464-410X.2009.08746.x

8. Sonmez NC, Coskun B, Arisan $S$, et al. Early penile metastasis from primary bladder cancer as the first systemic manifestation: A case report. Cases J 2009;2:7281. http://dx.doi.org/10.4076/17571626-2-7281

9. Hakenberg OW, Comperat EM, Minhas S, et al. EAU guidelines on penile cancer: 2014 update. Eur Urol 2015;67:142-50. http://dx.doi.org/10.1016/j.eururo.2014.10.017

10. Miyamoto $T$, Ikehara A, Araki M, et al. Cutaneous metastatic carcinoma of the penis: Suspected metastasis implantation from a bladder tumour. J Urol 2000;163:1519. http://dx.doi.org/10.1016/S0022$5347(05) 67658-6$

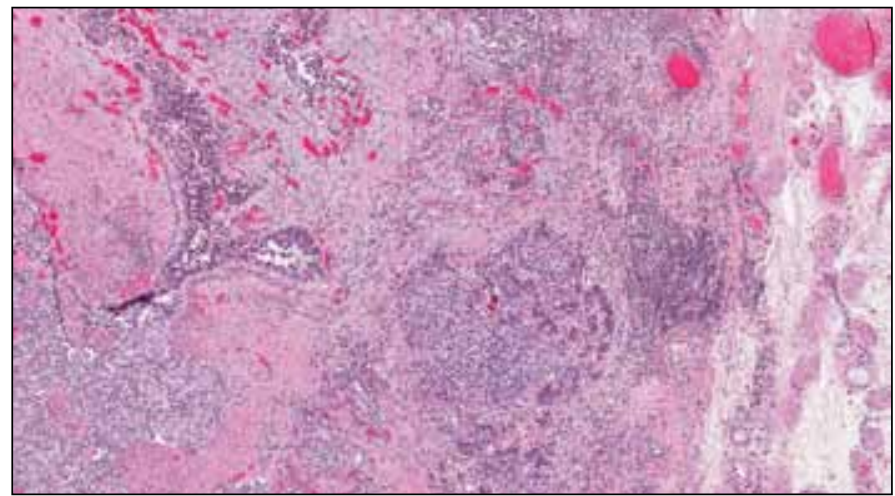

Fig. 2. Invasion of the corpus spongiosum with extensive desmoplastic stromal reaction (20x). 
Oake et al.

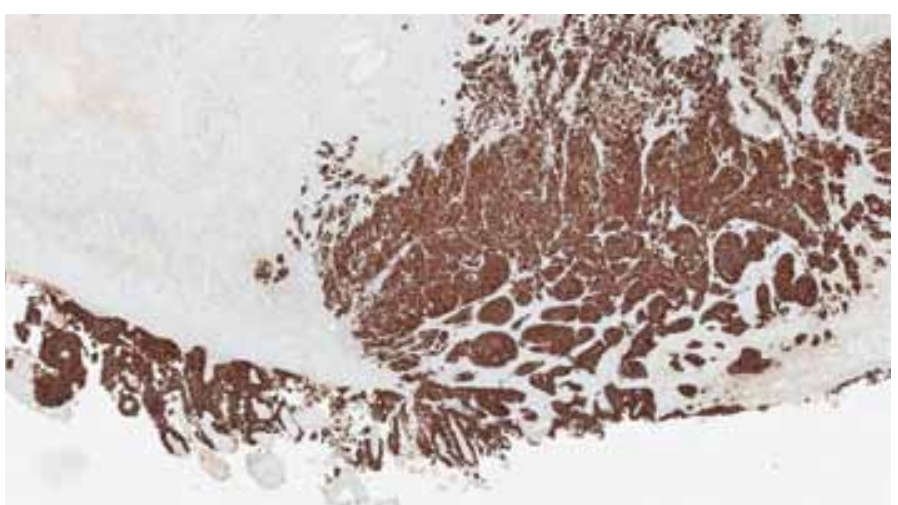

Fig. 3. Intense cytoplasmic staining of both papillary and invasive lesional cells with cytokeratin 7 (20x).
11. Paquin AJ Jr, Roland SI. Secondary carcinoma of the penis; a review of the literature and a report of nine new cases. Cancer 1956;9:626-32. http://dx.doi.org/10.1002/1097-0142(195605/06)9:3<626::AIDCNCR2820090330>3.0.C0;2-C

12. Bordeau KP, Lynch DF. Transitional cell carcinoma of the bladder metastatic to the penis. Urology 2004;63:981-3. http://dx.doi.org/10.1016/i.urology.2003.12.03

Correspondence: Dr. Justin D. Oake, Section of Urology, University of Manitoba, Winnipeg, MB, Canada; b96jdo@gmail.com 